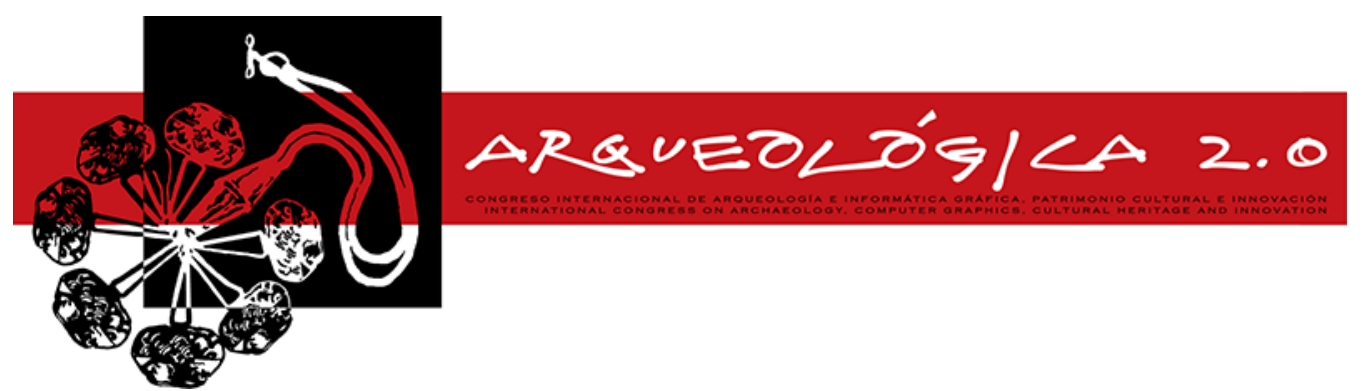

Proceedings of the $8^{\text {th }}$ International Congress on Archaeology, Computer Graphics, Cultural Heritage and Innovation

'ARQUEOLÓGICA 2.0 '

in Valencia (Spain),

Sept. $5-7,2016$

\title{
DIGITAL DOCUMENTATION OF INDUSTRIAL HERITAGE AT RISK: THE CASE OF PALATAKI AND THE OLD MINING COMPLEX AT LIMENARIA OF THASSOS (GREECE)
}

\author{
Nikolaos Lianos ${ }^{*}$, Anastasios Stamnas \\ Faculty of Architecture, Democritus University of Thrace, Greece. nlianos@arch.duth.gr
}

\begin{abstract}
:
Following completion of the 1st Workshop of Digital Documentation of Monuments Using 3d Laser Scanner organized by the Laboratory of Architectural Theory of Forms and Preservation Studies, Faculty of Architecture, DUTh, the present study was undertaken mainly to focus on the application of advanced techniques, such as the $3 \mathrm{~d}$ laser scanner, for the geometric documentation of the mining complex at the town of Limenaria of the island of Thassos, an abandoned and discredited monument for almost half a century. The key purpose of the laboratory work was the instruction of new technologies in surveying and documentation and their contribution to preservation, protection and restoration of monuments. The Field of practice was the former Speidel headquarters, known as "Palataki", and the abandoned mining complex at Limenaria, a unique example of industrial heritage at risk. The main objective of the laboratory was the documentation and the recording of this monument in order to protect it and highlight its historical value and cultural significance to the public.
\end{abstract}

Key words: cultural heritage, documentation, GIS, laser scanning, 3D modeling

\section{Introduction}

Industrial heritage refers to the physical remains of the history of technology and industry, such as manufacturing and mining sites, as well as power and transportation infrastructure. The industrial heritage of a region is an aspect of its cultural heritage. The international organization dedicated to the study and preservation of such heritage is The International Committee for the Conservation of the Industrial Heritage, known as $\mathrm{TICCIH}$. TICCIH has been ICOMOS's specialist adviser on industrial heritage since 2000 and assesses industrial sites for the World Heritage List.

According to $\mathrm{TICCIH}$ principles, the industrial heritage is highly vulnerable and often at risk to be lost for lack of awareness, documentation, recognition or protection, but also because of changing economic trends, negative perceptions, environmental issues or its sheer size and complexity (Lianos 2012). The first step to ensure effective protection and conservation of the industrial heritage structures, sites, areas and landscapes requires an up-to-date precise documentation and recording (context analysis, study at different scales, inventory of component parts and of impact, history of the town and its phases of evolution, etc.) (ICOMOS, The Dublin Principles, 2011). Moreover, as already stated by the
Nizhny Tagil Charter for the Industrial Heritage (2003), "recording is a fundamental part of the study of industrial heritage and a full record of the physical features and condition of a site should be made and placed in a public archive before any interventions are made".

Nowadays, technology has radically changed matters in documentation and promises to continue to bring more changes rapidly (Lerma et al. 2008). In contrast to other available techniques of documentation such as nonphotographic (graphic documentation, hand measuring and tachometry) and photographic (photography, rectified photography, computer-rectified photography, photogrammetry) techniques, $3 \mathrm{~d}$ laser scanning represents today the most advanced technology available for measuring and documenting objects, structures and landscapes (Patias et al. 2008, 2013). 3d laser scanners produce a huge number of $3 \mathrm{~d}$ points and the resulting three dimensional color point cloud can be used to extract CAD elements or to create a $3 d$ surface model (Remondino 2011). 3d laser scanners are widely used in the field of architectural and archaeological surveying and documentation of monuments thereby bringing new perspectives, and can satisfy most requirements of those types of applications (Haddad 2011).

In this context, the Laboratory of Architectural Theory of Forms and Preservation Studies, Faculty of Architecture, 
Democritus University of Thrace, Greece, organized the 1st Workshop of Digital Documentation of Monuments Using a 3d Laser Scanner at Limenaria of Thassos (Fig. 1) on May 2014. The main purpose was the instruction of new technologies in surveying and documentation, and their contribution to preservation, protection and restoration of monuments. The Field of practice was the former Speidel headquarters, known as "Palataki", and the entire abandoned mining complex at Limenaria, a unique example of industrial heritage at risk. The main objective of the laboratory was the documentation and recording of the monument in order to protect it and highlight its historical value and cultural significance to the public.

a)

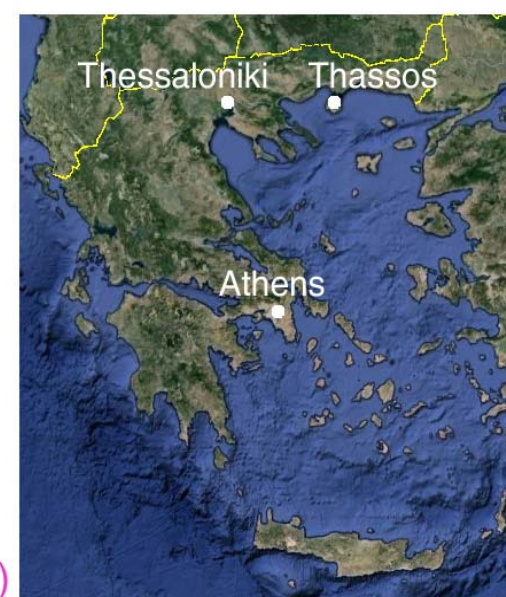

b)

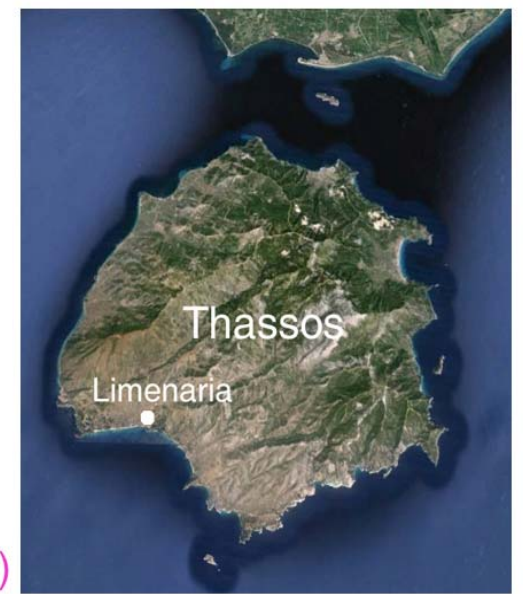

Figure 1: Map of Greece and the location of Thassos island (a) The location of Limenaria of Thassos (b) (Source: Gougle Earth).

\section{Case study: "Palataki" and the old mining complex}

\subsection{Brief mining history of Limenaria}

"Palataki" and the old mining complex (Fig. 2) are located at Limenaria of Thassos, a Greek island in the northern Aegean Sea, close to the coast of Thrace and the plain of the river Nestos, geographically part of Macedonia. Thassos possesses mineral wealth and mining activities for basic and precious metals dating as far back as the 7th century B.C. with the Phoenicians, followed in the 4th century by the Greeks and then the Romans.

In the early 20th century, mining companies such as "Speidel-Pforzeheim" (1905-1912) and "Veille Montagne \& Société Hellenique Metallurgique et Miniere" (19251930 ) exploited the island's Zinc-lead rich calamine ores. In 1905 a metallurgical plant was erected at Limenaria, the second largest town of the island, for the calcination of the calamines in vertical and Oxland furnaces to produce ZnO. Later (1926) the calcination plant was rebuilt by Vieille Montagne with Waelz system rotary furnaces. Iron ore mining became important during the years 1954-1964. Several mining companies (SchmidtKrupp and Apostolopoulos A.E., Chondrodimos S.A.) exploited the iron ore deposits of the island. It is estimated that total mineral production during the period 1905-1964 was about 2 million tonnes of calamine (12\% $\mathrm{Zn}+\mathrm{Pb})$ and 3 million tonnes of iron ore $(44 \% \mathrm{Fe})$. Since 1964 there has been no mining activity on the island.

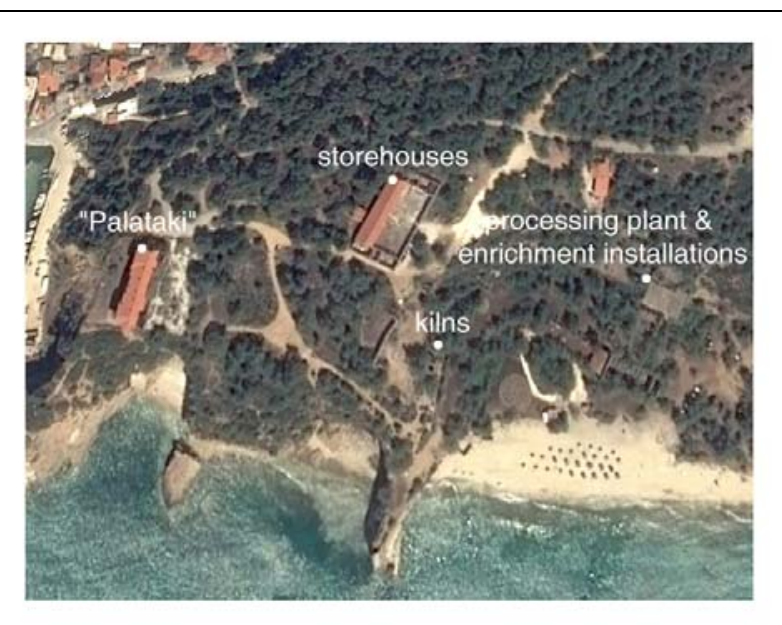

Figure 2: Map of the mining complex of Limenaria (Source: Google Earth).

\subsection{Analysis of the mining complex}

The impressive "Palataki" dominates the rocky cape where it stands just at the end of the Limenaria harbour (Fig. 3). It is a two-storey building, rectangular, with two small towers on its narrow facets. As a vivid example of eclectic architecture, it is characterized by a strict geometry and influenced from central European adherents. It was built between 1903 and 1904 to house the administration of Speidel, the German company which by then was exploiting the Thassos mines. In 1963 though, it stopped being used since the industrial installations were deserted.

Near "Palataki" there are the remains of the old storehouses, currently used as a makeshift folk-art museum. At the foot of the hill where "Palataki" stands, there is the picturesque beach of "Metalia" (Mines) where the old ore-enrichment installations lie. The old buildings cover the slope and, along with a heap of old rust dominate the scenery. The floors and walls are left naked, since all metal parts and machinery have been looted and sold as scrap.

The only installations preserved are the kilns (furnaces), part of the ore process, which in the early 1900s was performed by the company "Speidel-Pforzeheim" and 
later by its successor "Veille Montagne" (Fig. 4). After the 1930s recession, ore-processing was stopped and the great furnace-ramp was used only for hauling unprocessed ore to barges. Several other buildings complete the set of installations around the Limenaria area.

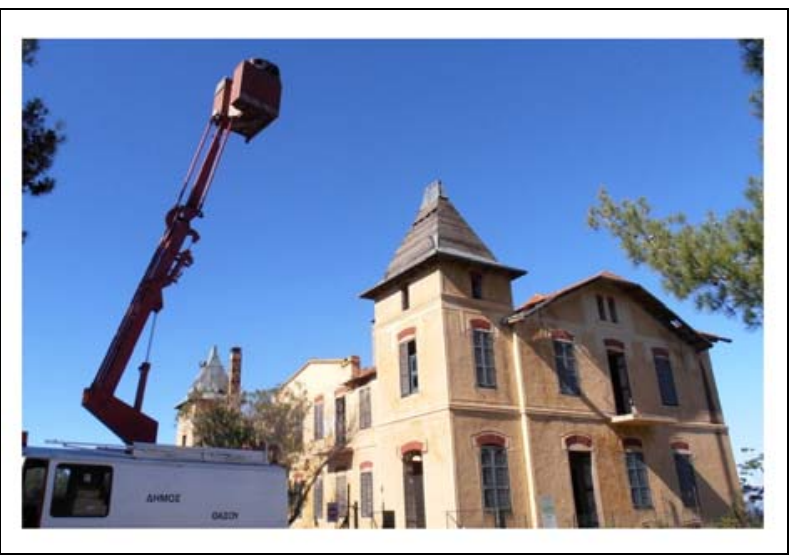

Figure 3: "Palataki" during data acquisition process.

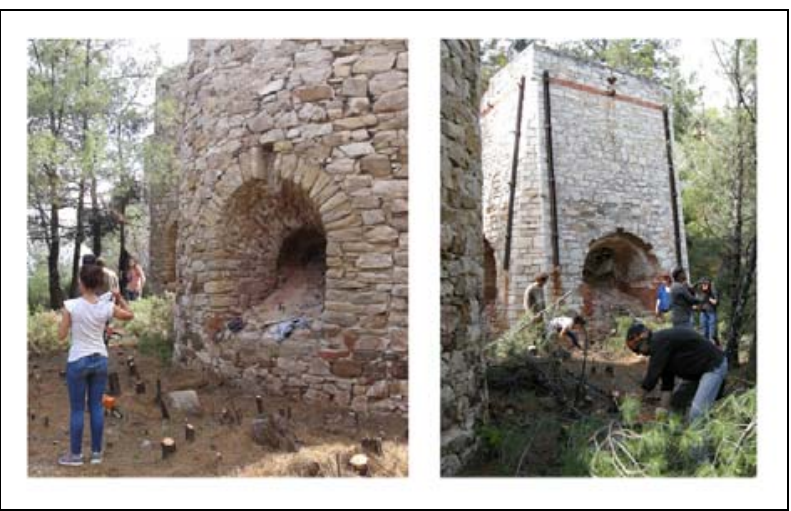

Figure 4: The kilns during vegetation removal.

\subsection{The importance of documentating the mining complex}

"Palataki" and the mining complex of Limenaria, including buildings, facilities, mining galleries and the surrounding landscape, is one of the most important industrial-mining complexes which are preserved intact in their original historical form in the Eastern Mediterranean.

According to the ICOMOS international charters, the International Charter for the Industrial Heritage of Nizhny Tagil, signed in 2003, and the specifications of $\mathrm{TICClH}$ (The International Committee for the Conservation of the Industrial Heritage), the mining complex of Limenaria constitutes a complete monument worthy of rescue and protection, in regards to integrity, authenticity and uniqueness.

Today, the obsolescence of this monument became an unfortunate reality. The monument has been at risk, abandoned and discredited for almost half a century, and there is no doubt that the first step towards ensuring its protection is the documentation of the whole mining complex. Therefore, everyone can easily understand that a complete documentation of the mining complex, using advanced technologies such as the $3 d$ laser scanner, can guarantee the basis for planning and execution of preservation and conservation works and a viable reuse of the monument.

\section{Organizing the workshop of digital documentation}

\subsection{Structure and goals of the workshop}

The focus of the $1^{\text {st }}$ Workshop of Digital Documentation of Monuments Using 3d Laser Scanning was organized at Limenaria of Thassos on May 2014 by the Laboratory of Architectural Theory of Forms and Preservation Studies (Faculty of Architecture, Democritus University of Thrace, Greece), and was targeted towards: a) the education and training on use of advanced technologies available for measuring and documenting objects, and the contribution of these technologies to the protection and restoration of monuments, and b) the digital documentation of the mining complex of Limenaria of Thassos in order to protect it and highlight its cultural value. To achieve these goals, the Worskshop began with the selection of buildings and sites to be captured using the $3 \mathrm{~d}$ laser scanner and, afterwards, the organization of field work and office work. To this end, the use of a work diary was considered an essential tool to manage the documentation work.

\subsection{Selection of buildings and sites}

The selection of buildings and site to be scanned was made on the basis of two factors: (i) the importance and the state of risk of each building, and (ii) the duration of the Workshop (six days). Thus, the selected buildings and sites (Fig. 5) to be scanned were as follows: (a) "Palataki" and the kilns (furnaces), (b) the platform above the kilns, (c) the road that connects "Palataki" and the platform, (d) the road that connects kilns (furnaces), and (e) the factory (processing plant and enrichment installations). Initially, the area around "Palataki" and the kilns was cleaned and a bunch of trees was removed in order to capture the selected buildings.

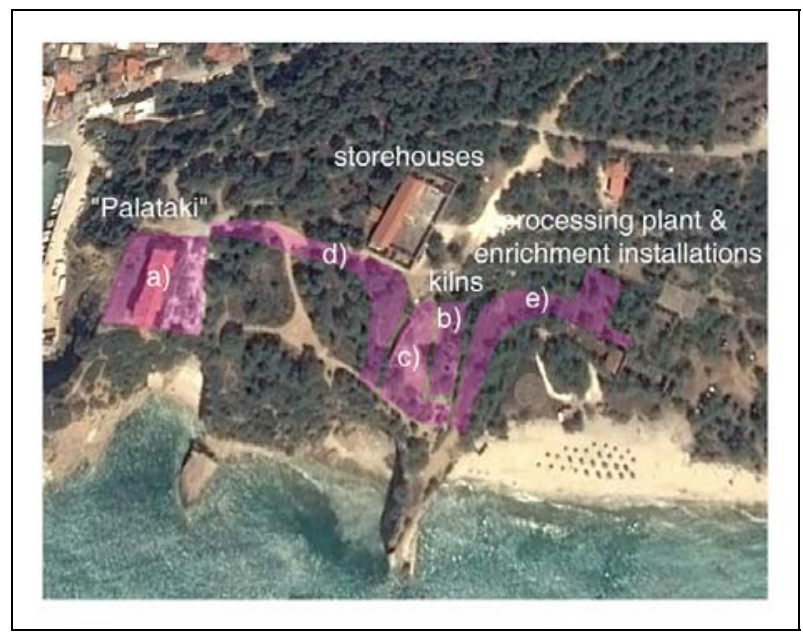

Figure 5: The selected buildings and sites to be scanned.

\subsection{Analysis of field measurements}

During data acquisition process, the "Faro focus $3 \mathrm{~d} X$ 120" laser scanner (Table. 1) was used for DSM collection and a significant number of 71 measurements 
were realized in order to capture the selected buildings and sites of the mining complex of Limenaria of Thassos.

Table 1: Technical details of the equipment

\begin{tabular}{c|c} 
Laser scanner & Faro focus $3 d \times 120$ \\
\hline Distance accuracy & up to $\pm 2 \mathrm{~mm}$ \\
Dynamic range & from $0.6 \mathrm{~m}$ up to $130 \mathrm{~m}$ \\
Noise reduction & $50,00 \%$
\end{tabular}

The Data acquisition process lasted for five days during the Workshop and while trying to organize field measurements and establish a methodology for conducting field works, certain steps were followed:

1. Delimitation of scan area.

2. Designing of sketches illustrating the positioning of the $3 \mathrm{~d}$ laser scanner and the location of ground control points (Fig. 6).

3. Selection of initial settings of the $3 d$ laser scanner (quality of scanning, scan resolution, scanning in color or in black-and-white etc.)

4. Placement of Bullets and targets (uniformly distributed over all scanned areas) in order to be used as homologous points to merge the different scans.

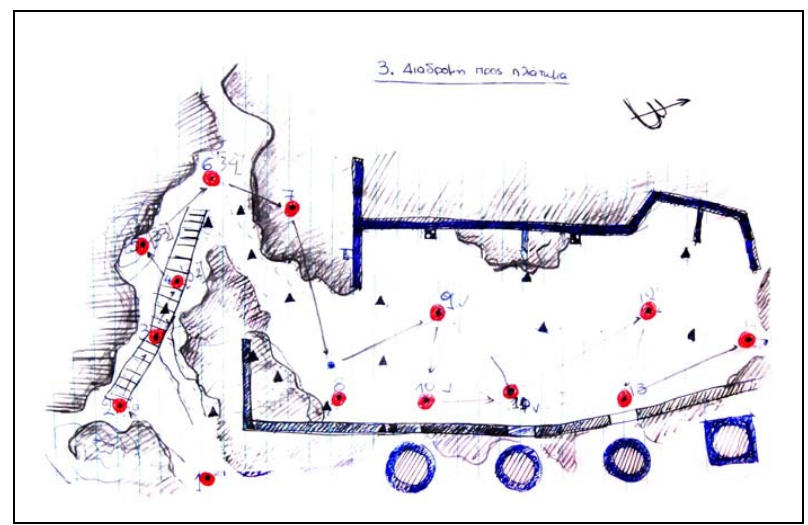

Figure 6: Design sketch illustrating the positioning of the 3d laser scanner and the location of ground control points during field work.

\subsection{Data processing}

Data processing lasted for four days using 4 powerful workstation PCs. Each workstation PC was used to merge a group of 17 stations and each merged group was copied into one workstation PC for the final merging of all stations. The point clouds of all stations (71) were merged using the FARO SCENE software specifically designed for the FARO laser scanner. During the registration stage, at least 3 pairs of homologous points were selected for each overlapping pair of point clouds. The images taken with the internal camera of the laser scanner were used for the coloring of the 3D points (Fig. 7 ). Then the model was exported from the faro scene software to the Bentley Pointools software in order to remove noise and areas of no interest. Finally, the model was used to create a high resolution animated video of the whole area scanned. The finalized "noise-free' model consisted of 5 billion points.

a)

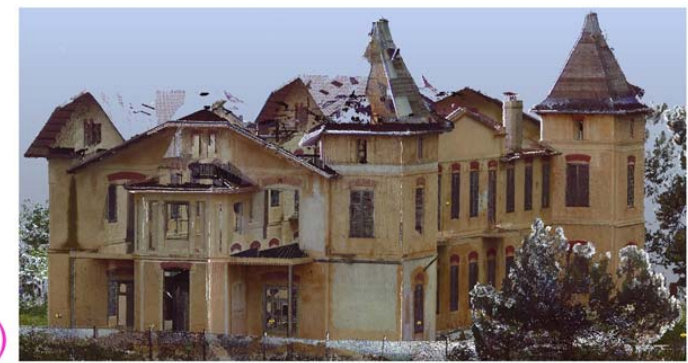

b)

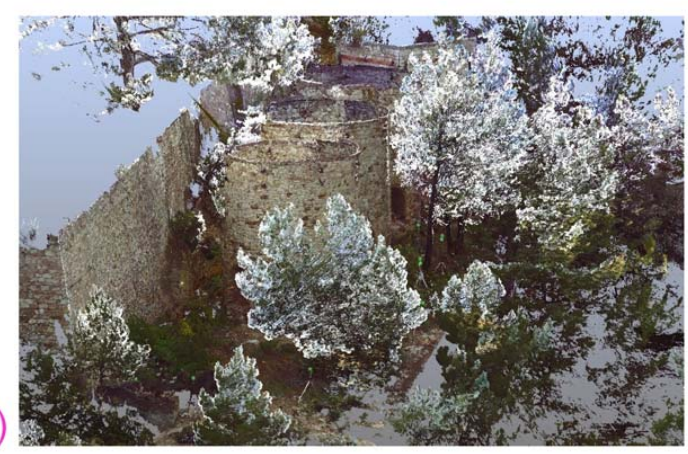

Figure 7: The colored point cloud of "Palataki" (a) and the kilns (b).

\section{Conclusions and future work}

3D laser scanning technology is a powerful tool not only to record historical sites and objects, but also for preservation purposes, for scientific research and environmental applications. Today, more than ever before, the application of 3D laser scanning to reconstruct and conserve heritage buildings, monuments and/or archaeological sites, is generally accepted as a method of choice to document cultural heritage owing to its accurate and fast characteristics. Thus, during the period of the current economic crisis when other laborrequiring approaches are not possible, accurate digital documentation of the present state of our cultural heritage, especially the one at particularly high risk, is very important as a reference and as a record for future generations.

In this context, the Laboratory of Architectural Theory of Forms and Preservation Studies, Faculty of Architecture, Democritus University of Thrace, intend to extend the activities of the Workshop of digital documentation of monuments using $3 \mathrm{~d}$ laser scaning in order to protect monuments at risk, such as the mining complex of Limenaria of Thassos, and highlight their historical value and cultural significance to the public.

\section{Acknowledgements}

We would like to express our sincere thanks and appreciation to Giorgos Agelis, Giorgos Vasilakis, Nikos Karagiannis, Ioanna Mpalioti, Ioannis Mourthos, Anna Boutou, Panagiota Spuropoulou, Eirini Tsetine and Maria loanna Photopoulou who attended the Workshop and helped with field measurements and data acquisition and processing. 


\section{References}

HADDAD N. A., 2011, From ground surveying to 3D laser scanner: A review of techniques used for spatial documentation of historic sites, Journal of King Saud University - Engineering Sciences, Volume 23, Issue, 2, pp. $109-118$.

LIANOS, N., 2012, “The Economic Crisis: Is the Protection of a Nation's Cultural Heritage Still Possible? The significance and the role of an accurate 3D documentation". From past experience to new approaches and synergies: the Future of Protection Heritage Management for Archaeological Heritage in Times of Economic Crisis, Athens, New Acropolis Museum, Nikos Lianos: LIMENARIA THASOS MINING COMPLEX, https://www.youtube.com/watch?v=dkJrnUxcnYs, https://www.youtube.com/watch?v=TEjIME7w3B4.

LERMA, J.L., VAN GENECHTEN, B., HEINE, E., SANTANA, M., 2008, 3D Risk Mapping. Theory and Practice on Terrestrial Laser Scanning, Training Material Based on Practical Applications, Universidad Politécnica de Valencia, Spain.

PATIAS, P., GEOGOULA, O., KAIMARIS, D., GEORGIADIS, CH., STYLIANIDIS, S., STAMNAS, A., 2008, 3D Mapping using Model Helicopter and Laser Scanning: case study activities of the laboratory of Photogrammetry and Remote Sensing, AUTh, 14th International Conference on Virtual Systems and Multimedia (VSMM) dedicated to Cultural Heritage, Nicosia, Cyprus, pp.1-5.

PATIAS, P., KAIMARIS, D., GEORGIADIS, CH., STAMNAS, A., ANTONIADIS, D., PAPADIMITRAKIS D., 2013, 3d mapping of cultural heritage: special problems and best practices in extreme case-studies, ISPRS Annals of the Photogrammetry, Remote Sensing and Spatial Information Sciences, Volume II-5/W1, 2013, XXIV International CIPA Symposium, Strasbourg, France, pp. 223-228.

REMONDINO F., 2011, Heritage Recording and 3D Modeling with Photogrammetry and 3D Scanning. Remote Sensing $3(1)$, pp. 1104-1138, doi:10.3390/rs3061104. 